perm function and structure and seminal plasma prostanoid concentrations in men with IDDM. Diabetes Care 1989;12:742-4.

67 Badenoch DF, Evans SJW MeCloskey DJ Sperm density measurement: should this be aband S

68 Pol PS, Beuscart R, Leroy-Martin B, Hermand E, Jablonski W. Circannual rhythm of sperm parameters of fertile men. Fertil Steril 1989;51:1030-3.

69 Sobowale OB, Akiwumi O. Testicular volume and seminal fluid profile in fertile and infertile males in Ilorin, Nigeria. Int $\mathcal{F}$ Gynecol Obstet 1989;28. 155-61.

70 Bonde JP. Semen quality and sex hormones among mild steel and stainless steel welders: a cross sectional study. Br F Ind Med 1990;47:508-14.

71 Chan SYW, Wang C, Song BL, Lo T, Leung A, Tsoi WL, et al. Computerassisted image analysis of semen concentration in human semen before and after swim-up separation: comparison with assessment by haemocytometer. Int $\mathcal{A}$ Androl 1989;12:339-4

72 Neuwinger J, Behre HM, Nieschlag E. External quality control in the andrology laboratory: an experimental multicenter trial. Fertil Steri 1990;54:308-14.

73 Boyle P, Kaye SN, Robertson AG. Changes in testicular cancer in Scotland. Eurf Cancer Clin Oncol 1987;23:827-30.

74 Osterlind A. Diverging trends in incidence and mortality of testicular cancer in Denmark, 1943-1982. Br f Cancer 1986.53.501-5.

75 Brown LM, Pottern LM, Hoover RN, Devesa SS, Aselton P. Flannery JT.
Testicular cancer in the United
Int 7 Epidemiol 1986;15:164-70.

76 Hakulinen T, Andersen AA, Malker B, Pukkala E Schou G, Tulinius H. Trends in cancer incidence in the Nordic countries. APMIS 1986;suppl 288.

77 Berthelsen JG, Skakkebæk NE. Gonadal function in men with testis cancer. Fertil Steril 1983;39:68-75.

78 Jackson MB, John Radcliffe Hospital Cryptorchidism Research Group. The epidemiology of cryptorchidism. Horm Res 1988;30:153-6.

79 An increasing incidence of cryptorchidism and hypospadias? Lancet 1985;

80 Testicular descent revisited. Lancet 1989;i:360-1

81 Bostofte E, Serup J, Rebbe H. Relation between sperm count and semen volume, and pregnancies obtained during a twenty-year follow-up period. Int $\mathcal{F}$ Androl 1982;5:267-75.

82 Henderson BE, Benton B, Jing J, Yu MC, Pike MC. Risk factors for cancer of the testis in young men. Int $f$ Cancer 1979;23:598-602.

83 Henderson BE, Ross RK, Pike MC, Casagrande JT. Endogenous hormones as a major factor in human cancer. Cancer Res 1982;42:3232-9.

84 Santti R, Pylkkänen L, Newbold R, McLachlan JA. Developmental oestrogenization and prostatic neoplasia [editorial]. Int $\mathcal{F}$ Androl 1990;13:77-80.

(Accepted 7 fulv 1992)

\title{
Metabolic acidosis and fatal myocardial failure after propofol infusion in children: five case reports
}

\author{
T J Parke, J E Stevens, A S C Rice, C L Greenaway, R J Bray, P J Smith, C S Waldmann, C Verghese
}

\section{Abstract}

Objective-To examine the possible contribution of sedation with propofol in the deaths of children who were intubated and required intensive care.

Design-Case note review.

Setting-Three intensive care units.

Subjects-Five children with upper respiratory tract infections aged between 4 weeks and 6 years.

Results-Four patients had laryngotracheobronchitis and one had bronchiolitis. All were sedated with propofol. The clinical course in all five cases was remarkably similar: an increasing metabolic acidosis was associated with bradyarrhythmia and progressive myocardial failure, which did not respond to resuscitative measures. All children developed lipaemic serum after starting propofol. These features are not usually associated with respiratory tract infections. No evidence was found of viral myocarditis, which was considered as a possible cause of death.

Conclusion-Although the exact cause of death in these children could not be defined, propofol may have been a contributing factor.

\section{Introduction}

Acute respiratory tract infections are common in infants and children. Most run a short self limiting course, requiring only treatment of symptoms. Even if intubation and ventilation are required the prognosis is usually excellent in previously fit children. Deaths in children presenting with such infections raise concerns that secondary factors, unrelated to the disease itself, may be implicated.

Propofol was introduced as an anaesthetic but more recently has been used for sedating patients in the intensive care unit. We are concerned that it may have played a part in the deaths of the five children described here.

\section{Case reports}

CASE 1

A previously fit girl aged 2 years 9 months (weight $12.5 \mathrm{~kg}$ ) was admitted with a 24 hour history of increasing stridor. On examination she had a fever of $38.5^{\circ} \mathrm{C}$, inspiratory stridor, and signs of upper airways obstruction. Diagnostic endoscopy and therapeutic tracheal intubation were done under general anaesthesia. At laryngoscopy the epiglottis appeared normal. Her trachea was intubated and purulent secretions aspirated. Acute bacterial laryngotracheobronchitis was diagnosed.

She was transferred to the general intensive care unit for artificial ventilation. A propofol infusion $(10 \mathrm{mg} / \mathrm{ml}$ in $10 \%$ Intralipid) was started at $4.8 \mathrm{mg} / \mathrm{kg} / \mathrm{hour}$. Culture of the tracheal aspirate yielded a pure growth of Branhamella catarrhalis, and treatment with amoxycillin and flucloxacillin was started. The white cell count was raised $\left(24 \times 10^{9} / 1 ; 80 \%\right.$ neutrophils). Serum biochemistry tests and chest radiography gave normal results. Over the next 24 hours her fever settled and the white count returned to normal. After 48 hours a gas leak developed around the endotracheal tube and she was extubated. However, stridor persisted and the trachea was reintubated three hours later. Increasing doses of propofol were required to maintain adequate sedation.

On day 4 she developed nodal bradycardia (rate $70 \mathrm{bpm}$ ) with a right bundle branch block pattern, which was unresponsive to intravenous atropine $0.6 \mathrm{mg}$. Despite the arrhythmia her blood pressure and oxygen saturation remained satisfactory, but mild metabolic acidosis was noted (base excess $-7 \cdot 1 \mathrm{mmol} / \mathrm{l})$. On day 5 her condition deteriorated rapidly and her core temperature rose to $41 \cdot 3^{\circ} \mathrm{C}$. She of was peripherally vasoconstricted and hepatomegaly $\frac{T}{0}$ was noted. The central venous pressure rose to $18 \mathrm{~cm}$ water. Blood specimens were lipaemic and the propofol $N$ infusion was stopped. Sepsis was thought to have N caused her deterioration. A lumbar puncture and 0 abdominal ultrasonography (which also excluded pericardial fluid) gave normal results. Cefotaxime was added to the antibiotic regimen, but no organisms were isolated from any cultures.

She required dobutamine, dopamine, isoprenaline, and adrenaline infusions in increasing doses to maintain circulation. Her inspired oxygen concentration was gradually increased to $100 \%$. However, the bradycardia persisted and the acidaemia worsened (base excess $-11.8 \mathrm{mmol} / \mathrm{l}, \mathrm{pH} 7 \cdot 14)$; this proved refractory to Tris buffer. She died on day 5 of a pharmacologically resistant asystole.

Postmortem examination showed severe congestion of the epiglottis, larynx, trachea, and bronchi. The lungs were congested and oedematous, with no 
evidence of pus. The heart was slightly enlarged but macroscopically normal. Microscopy of the myocardium showed severe myocytolysis but no genuine myocarditis. The liver was pale and microscopy showed microvesicular fatty change.

CASE 2

A 16 month old girl (weight $10 \cdot 1 \mathrm{~kg}$ ) was admitted with a 24 hour history of croup and fever $\left(38 \cdot 0^{\circ} \mathrm{C}\right)$. Over the next 12 hours her condition deteriorated and she required tracheal intubation. At laryngoscopy the epiglottis appeared normal, but the vocal cords were moderately inflamed. She was transferred to the general intensive care unit for ventilation. A propofol infusion was started $(7.9 \mathrm{mg} / \mathrm{kg} / \mathrm{hour})$ in combination with morphine. Chest radiography showed bilateral patchy consolidation, which was treated with cefotaxime and flucloxacillin.

On the second day her fever settled, but metabolic acidosis was noted (base excess $-10.5 \mathrm{mmol} / \mathrm{l}$, arterial carbon dioxide pressure $3 \cdot 3 \mathrm{kPa}, \mathrm{pH} \mathrm{7} \cdot 30$ ). On day $3 \mathrm{a}$ leak developed around the endotracheal tube, and she was extubated. The trachea was reintubated after 30 minutes when stridor recurred. On day 4 she became feverish again. On day 5 she developed nodal bradycardia with a right bundle branch block, and hepatomegaly was noted. She became oliguric despite treatment with dopamine $(2 \mu \mathrm{g} / \mathrm{kg} / \mathrm{min})$ and frusemide. Her plasma potassium concentration was $6.9 \mathrm{mmol} / \mathrm{l}$, which was treated with calcium resonium enemas and glucose-insulin infusion. Dobutamine, and subsequently adrenaline and isoprenaline, were required to maintain the circulation. Her blood specimens were lipaemic and the propofol infusion was stopped.

On day 6 she required peritoneal dialysis to control hyperkalaemia and pulmonary oedema. Bolus doses and infusions of adrenaline and isoprenaline were used to treat episodic bradyarrhythmia. Arterio-venous haemofiltration was started to treat the acidaemia and fluid overload. However, several hours later she developed asystole and could not be resuscitated. Consent for a postmortem examination was not granted.

\section{CASE 3}

A 22 month old girl (weight $12.5 \mathrm{~kg}$ ) was admitted to hospital with acute stridor, cyanosis, and a history of hoarseness, sore throat, and fever $\left(38^{\circ} \mathrm{C}\right)$ over the preceding 24 hours. Her trachea was intubated, and she was transferred to the regional paediatric intensive care unit. At laryngoscopy the epiglottis appeared normal but the arytenoid cartilages were red and swollen.

She was sedated with midazolam and morphine, both at $0 \cdot 05-0 \cdot 1 \mathrm{mg} / \mathrm{kg} / \mathrm{hour}$ to enable ventilation, and dexamethasone $0.5 \mathrm{mg} / \mathrm{kg}$ was given. In the evening of day 2 a leak occurred around the tube and the sedation regimen was changed to propofol to allow easy awakening for extubation the next morning. However, overnight her temperature rose to $39^{\circ} \mathrm{C}$ and patchy consolidation in both lung fields was seen in the chest radiograph. Cefuroxime was started, and she required inspired oxygen concentrations of $80 \%$ to maintain a satisfactory arterial oxygen saturation. The sedation was changed to a propofol infusion, $10 \mathrm{mg} / \mathrm{kg} / \mathrm{hour}$, as planned. Her condition remained unchanged for the next two days, except that on day 5 she developed metabolic acidosis with a base excess of $-9.2 \mathrm{mmol} / \mathrm{l}$. All cultures were negative. The base excess returned to $-1.5 \mathrm{mmol} / \mathrm{l}$ after treatment with 15 millimoles of sodium bicarbonate.

On day 6 she suddenly developed bradycardia, which proceeded rapidly to asystole. Full resuscitation was initially successful, but high dose inotropic support was needed to sustain the circulation. Except for recurrence of the acidosis, blood biochemistry tests, including ammonia and liver function tests, and haematology gave normal results but the specimens were lipaemic. Echocardiography and computed tomography of the brain showed no abnormality. She continued to deteriorate and pacing electrodes were applied directly to the myocardium at thoracotomy. After initial capture the threshold rapidly increased until no paced beats were evident, and she died seven hours later.

Postmortem examination showed bilaterally consolidated lungs with histological changes suggestive of an interstitial pneumonia, probably viral. The heart was normal, with no evidence of myocarditis. There was fatty infiltration of the liver. Specimens taken to investigate microbiology and virology gave negative results.

\section{CASE 4}

A four week old girl was admitted with a clinical diagnosis of bronchiolitis. On examination she was afebrile but had a tachycardia of $160 \mathrm{bpm}$ and a tachypnoea of $60 / \mathrm{min}$ with widespread crackles over both lung fields. Respiratory syncytial virus was later identified in her nasopharyngeal secretions.

On the day after admission she deteriorated and became cyanosed and pale. She was transferred to the general intensive care unit, where her trachea was intubated and positive pressure ventilation started. A propofol infusion $(7 \cdot 1-10 \cdot 7 \mathrm{mg} / \mathrm{kg} /$ hour $)$ was used for sedation. An arterial blood sample taken at the start of artificial ventilation had a $\mathrm{pH}$ of 7.6 and a base excess of $1.8 \mathrm{mmol} / \mathrm{l}$

The propofol infusion was continued throughout the next day and by the following morning she had developed metabolic acidosis with an arterial $\mathrm{pH}$ of $7 \cdot 3$ and a base excess of $-12.3 \mathrm{mmol} / \mathrm{l}$. By midday her metabolic acidosis had increased (arterial pH 7.05, base excess $-17 \cdot 3 \mathrm{mmol} / \mathrm{l}$ ) and her serum had become lipaemic.

On day 5 she had a period of bradycardia with frequent atrial ectopics. An echocardiogram showed no abnormality but viral myocarditis was postulated. The propofol infusion was stopped but her metabolic acidosis increased with the arterial $\mathrm{pH}$ reaching 6.94 and the base excess $-22.8 \mathrm{mmol} / \mathrm{l}$. The bradycardia responded only limitedly to intravenous boluses of atropine, but an isoprenaline infusion increased the heart rate from 60 to $90 \mathrm{bpm}$. Her liver edge had become palpable $5 \mathrm{~cm}$ below the costal margin. She had established renal failure, and peritoneal dialysis was started on day 6 . In addition, she was unresponsive to painful stimuli, although the propofol had been stopped 24 hours before. Her serum ionised calcium concentration was considerably below the normal range at $0.68 \mathrm{mmol} / \mathrm{l}$ (reference range $1 \cdot 19-1 \cdot 37 \mathrm{mmol} / \mathrm{l})$.

The following morning her skin perfusion progressively deteriorated. She had fixed, dilated pupils and remained completely unresponsive and died after active treatment was stopped. Permission for a postmortem examination was refused.

\section{CASE 5}

A 6 year old boy was treated by his general practitioner with orciprenaline and ampicillin after an episode of wheezing. The next morning he developed stridor and was admitted to a local hospital where his antibiotic regimen was changed to amoxycillin and chloramphenicol. Later that day he deteriorated and his trachea was intubated. His epiglottis was normal but his subglottic stenosis was so severe that only a tracheal tube with an internal diameter of $3.5 \mathrm{~mm}$ 
could be passed. He was transferred to a general intensive therapy unit, where he was reintubated with a larger tracheal tube $(4.5 \mathrm{~mm})$, sedated with a propofol infusion $(4-9 \cdot 2 \mathrm{mg} / \mathrm{kg} / \mathrm{hour}$ ), and allowed to breathe spontaneously. A parainfluenza type 2 virus was later isolated from his tracheal aspirate.

In the early hours of the next day (day 2 ) an arterial blood sample showed metabolic acidosis ( $\mathrm{pH} 7 \cdot 24$ and a base excess of $-9.5 \mathrm{mmol} / \mathrm{l})$. On day 3 he was extubated under general anaesthesia but needed to be reintubated within 30 minutes. A blood specimen was reported to be lipaemic, as were all subsequent blood samples.

On day 4 the tracheal tube was changed after it had blocked with secretions. Arterial blood samples showed progressive metabolic acidosis with base excesses of $-10 \cdot 8,-11 \cdot 8,-12 \cdot 9$, and $-16 \mathrm{mmol} / \mathrm{l}$. His general condition deteriorated and he was thought to have septicaemia. Ceftazidime was substituted for chloramphenicol and metronidazole added. A sputum sample grew Pseudomonas aeruginosa. He was paralysed and positive pressure ventilation started. Shortly after this his heart rate fell suddenly from 180 to $90 \mathrm{bpm}$. The electrocardiogram showed a varying PR interval and he rapidly became hypotensive and anuric. Both the bradycardia and the hypotension were unresponsive to atropine, dobutamine, and adrenaline. Transvenous pacing was attempted but was unsuccessful and he died shortly afterwards from a progressive bradycardia leading to asystole. The propofol infusion had been stopped about three hours before death.

A postmortem examination showed massive cerebral oedema. There was no structural abnormality of the heart apart from a small pericardial effusion $(40 \mathrm{ml})$ and no evidence of myocarditis. Severe tracheobronchitis with subglottic narrowing was seen. The liver weighed $950 \mathrm{~g}$ and was firm and pale and appeared fatty. Microvesicular steatosis was confirmed on microscopy. The kidneys showed tubular debris and degenerative changes in the epithelial cells but no glomerulonephritis.

\section{Discussion}

The children in these case reports showed remarkable similarity of clinical features and disease course. They all required tracheal intubation within 24 hours of the onset of symptoms and ventilation throughout most of their illness. Metabolic acidosis was an early feature. Death was ultimately caused by refractory bradyarrhythmia progressing to asystole. All five children were sedated with propofol and developed lipaemic serum. The first three cases occurred during four weeks in early winter in two units in Oxford region whereas cases 4 and 5 occurred in Newcastle and were separated by eight months.

These cases are unique in our clinical experience. In Oxford, for example, in the 10 years preceding these cases 79 children were admitted to the paediatric intensive care unit with laryngotracheobronchitis with no deaths or serious illness. Case 3 was the first child to receive long term sedation with propofol in the unit. Persistent metabolic acidosis and myocardial failure are not usually features of laryngotracheobronchitis and require explanation. Echocardiography and necropsy showed no evidence of structural heart disease or cardiomyopathy, and Reyes syndrome (which shares some of the features seen in these children) was discounted on clinical and biochemical grounds.

Viral myocarditis may present as arrhythmia, sudden death, or congestive cardiac failure ${ }^{1}$ and was considered the most likely cause of death in these patients. However, there was little evidence to support this diagnosis.
POSSIBLE CONTRIBUTION OF INTRALIPID

Propofol is solubilised as a $1 \%$ solution in an oil-water emulsion (essentially $10 \%$ Intralipid) and has a $\mathrm{pH}$ of $7 \cdot 8$. The maximum recommended rate of infusion of $10 \%$ Intralipid in infants is $1.7 \mathrm{ml} / \mathrm{kg} / \mathrm{hour}$ (Intralipid data sheet, Kabi-Pharmacia, Milton Keynes, United Kingdom). The maximum infusion rates used in these cases were less than half this rate so the fat content of propofol mixture is unlikely to be the sole cause of the deaths.

Nevertheless, lipaemic serum was observed in allo five cases after three or more days of propofol infusion. This indicates inadequate clearance of fat, although $\frac{\bar{m}}{2}$ serum triglyceride concentration is a better indicator. ${ }^{23} \overrightarrow{\mathrm{D}}$ Triglycerides and cholesterol concentrations in adults do not increase for the first 72 hours of infusion. Thereafter both increase, and triglyceride concentra- tions may reach four times normal after six days. ${ }^{4}$ Pancreatitis may also be caused by severe hyper- $\omega$ triglyceridaemia. However, there was no evidence of pancreatitis in the cases described and in its absence raised serum triglyceride concentration would not account for the cardiovascular collapse.

In critically ill patients sympathetic stimulation, cortisol, and growth hormone all increase lipolysis and + fat oxidation even if carbohydrate is supplied. This $\rightarrow$ results in a large increase in non-esterified fatty acids, $\omega$ which are a valuable energy source. The liver converts $\triangle$ excess fatty acids to ketone bodies, which are also a $\vec{N}$ valuable energy source but can contribute to acidosis. $(\mathcal{D}$ Intralipid can also contribute to acidosis by impairingo liver function. Fat is deposited in the liver in any $\frac{\mathbb{D}}{3}$ condition where there is a rapid turnover of lipid ${ }^{5}$ ando was observed at necropsy in cases 1,3 , and 5 . Although $\stackrel{\mathbb{\complement}}{-}$ results of liver function tests remained normal, $\vec{c}$ impaired hepatic handling of lactate may have N contributed to acidosis. This is speculative since lactate levels were not measured in these cases, and the acidosis was not pursued as vigorously as perhaps it should have been.

PROPOFOL IN ADULTS

The use of propofol infusions for intensive care $\overline{\bar{a}}$ sedation in adults has been well documented. In $\mathrm{a}^{\exists}$ multicentre trial comparing propofol with midazolam in 101 critically ill patients (average infusion rates: $1.77 \mathrm{mg} / \mathrm{kg} / \mathrm{hour}$ ) blood pressure was slightly reduced in both groups and heart rate was lower in the propofol group. ${ }^{6}$ Recovery was more rapid with propofol, whicho was thought to compare favourably with midazolam. Harris et al sedated 15 ventilated patients for upô to 189 hours using propofol infusions of up to $3.73 \mathrm{mg} / \mathrm{kg} /$ hour. $^{7}$ Bolus doses of papaveretum were윽 added as required. Beller $e t a l^{8}$ used rates of up ton $3 \mathrm{mg} / \mathrm{kg} /$ hour for 96 hours to assess recovery time. In each case recovery was rapid, and no evidence ofo accumulation seen. Cook ${ }^{4}$ used propofol as the sole agent for six days in 10 ventilated patients. Most patients received 300 to $400 \mathrm{mg} /$ hour, but somew required $500 \mathrm{mg} /$ hour. Blood pressure fell by $30 ₹$ $40 \mathrm{~mm} \mathrm{Hg}$ but there were no associated changes ine heart rate. Recommended infusion rates for intensive care in adults are $1-4 \mathrm{mg} / \mathrm{kg} /$ hour. $^{9}$

\section{EFFECTS OF PROPOFOL}

Propofol causes systemic vasodilatation and a relative bradycardia, possibly by resetting the baroreceptor reflex. ${ }^{10}$ The fall in pulse rate is greater in children, perhaps because of their higher resting vagal tone. "م Children require comparatively larger doses than adults for both induction and maintenance of anaes thesia because of pharmacokinetic and pharmaco- $?$ dynamic factors. ${ }^{12}$

Propofol is metabolised in the liver to quinol glucuronides, propofol glucuronide, and 4-quinol 
sulphate, with propofol glucuronide predominating. The $\mathrm{pKa}$ of glucuronides is generally $3-4$, whereas that of the sulphate is less than 1 . The plasma half life of propofol glucuronide after a single dose in the dog is 80 minutes and the other metabolites probably have a similar profile (ICI Pharmaceuticals, metabolic section, personal communication). Accumulation of inactive metabolites may have contributed to the acidosis in our cases and perhaps to the neurological dysfunction described by Trotter and Serpell. ${ }^{13}$

\section{PROPOFOL SEDATION IN CHILDREN}

Experience of propofol for sedation in paediatric intensive care is limited. Norreslet and Wahlgreen ${ }^{14}$ reported its use in a 6 year old patient with croup for 44 hours. The mean infusion rate was $1.5 \mathrm{mg} / \mathrm{kg} / \mathrm{hour}$, and the child was extubated 30 minutes after the infusion was stopped. Bradycardia did not occur. Trotter and Serpell ${ }^{13}$ described temporary neurological sequelae in two children after infusions of propofol in intensive care and suggested it should not be used as the sole agent for sedation in children. Despite the lack of data Matthews found that propofol was used occasionally by 14 out of the 15 paediatric intensive care units in the United Kingdom replying to a questionnaire $^{15}$; three units reported frequent use of propofol, although the manufacturers do not recommend it for long term sedation in children. ${ }^{16}$ Recommended infusion rates for maintenance of anaesthesia in children over 3 years are $9-15 \mathrm{mg} / \mathrm{kg} /$ hour. ${ }^{9}$ The table shows the average and maximum infusion rates of propofol used in our cases. These rates are greater than those required for sedation of adults in intensive care but comparable with paediatric anaesthetic infusion rates.

Average and maximum infusion rates $(\mathrm{mg} / \mathrm{kg} / \mathrm{h})$ of propofol in five children with ventilation failure caused by upper respiratory tract infections

\begin{tabular}{lccc}
\hline & $\begin{array}{c}\text { Total infusion time } \\
\text { (hours) }\end{array}$ & Average rate & $\begin{array}{c}\text { Maximum rate } \\
\text { (duration (hours)) }\end{array}$ \\
\hline Case 1 & 115 & $7 \cdot 5$ & $11 \cdot 5(6)$ \\
Case 2 & 66 & $7 \cdot 4$ & $8 \cdot 0(29)$ \\
Case 3 & 76 & $10 \cdot 0$ & $13 \cdot 6(8)$ \\
Case 4 & 74 & $8 \cdot 0$ & $10 \cdot 7(5)$ \\
Case 5 & 104 & $8 \cdot 1$ & $9 \cdot 2(1)$ \\
\hline
\end{tabular}

\section{CONCLUSIONS}

We described five cases of fatal myocardial failure complicating respiratory tract infection in children. The onset of metabolic acidosis, bradyarrhythmia, and heart failure were originally ascribed to sepsis or a viral myocarditis. However, no clinical or pathological evidence was found for either diagnosis. These cases coincided with the use of high dose propofol infusions for sedation. There is no single ideal sedative for use in intensive care, thus almost any new anaesthetic drug, particularly if it has a short half life and thus allows a rapid recovery, will be examined as a suitable sedative whether it is licensed for such use or not. Propofol was thought to be appropriate in these cases in which early extubation was expected. Many drugs regularly used in anaesthesia and intensive care are not licensed for use in paediatrics, ${ }^{17}$ and extrapolation from adult experience is questionable bearing in mind the differing physiology and disease spectrum encountered in paediatric practice. Perhaps the most important lesson to be learnt from these cases is that using a mixture of complementary analgesic, sedative, and relaxant agents at doses well below their potential toxic range is safer than using a single agent at a necessarily high dose. Propofol will probably prove safe at a lower dose than used in these children, but until further data delineating the appropriate dose range are available it should not be used in paediatric intensive care.

We thank Dr C L Newman, consultant paediatrician and Dr N P Mann, consultant paediatrician, Royal Berkshire Hospital, Reading; Drs C San Lazaro and R Nelson, department of child health, Royal Victoria Hospital, Newcastle upon Tyne; and Professor E R Moxon, department of paediatrics, John Radcliffe Hospital, Oxford, for allowing us to report on their patients.

1 Weatherall DJ, Ledingham JGG, Warrell DA, eds. Oxford texthook of medicine. 2nd ed. Oxford: Oxford University Press, 1987:13.197-9.

2 Bedrick AD. Metabolic tolerance of parenteral lipids in neonates. A $m$ f Dis Child 1988;142:135-6.

3 Eddelston JM, Shelley MP. The effect on serum lipid concentrations of a prolonged infusion of propofol-hypertriglyceridaemia associated with propofol administration. Intensive Care Med 1991;17:424-6.

4 Cook S, Palma O. Propofol as a sole agent for prolonged infusion in intensive care. Fournal of Drug Development 1989;2(suppl 2):65-7.

5 Guyton AC. Textbook of medical physiology. 8th ed. Philadelphia: W B Saunders, 1991:754-60.

6 Aitkenhead AR, Pepperman ML, Willatts SM, Coates PD, Park GR, Bodenham AR, et al. Comparison of propofol and midazolam for sedation in critically ill patients. I.ancet 1989;ii:704-9.

7 Harris CE, Grounds RM, Murray AM, Lumley J, Royston D, Morgan $M$ Propofol for long-term sedation in the intensive care unit. Anuesthesia 1990;45:366-72.

8 Beller JP, Pottecher T, Lugnier A, Mangin P, Otteni JC. Prolonged sedation with propofol in ICU patients: recovery and blood concentration changes during periodic interruptions in infusion. Br J Anaesth 1988;61:583-8.

9 British Medical Association, Royal Pharmaceutical Sociery of Great Britain. British national formulary. No 23 (March). London: BMA, RPSGB 1992:450.

10 Claeys MA, Gepts E, Camu F. Haemodynamic changes during anaesthesia induced and maintained with propofol. Brf Anaesth 1988;60:3-9.

11 Short SM, Aun CST. Haemodynamic effects of propofol in children. Anaesthesia 1991;46:783-5.

12 Marsh B, White M, Morton N, Kenny GNC. Pharmacokinetic model driven infusion of propofol in children. $\mathrm{Br} \mathcal{F}$ Anuesth 1991;67:41-8.

13 Trotter C, Serpell MG. Neurological sequelae in children after prolonged propofol infusion. Anaesthesia 1992;47:340-2.

4 Norreslet J, Wahlgreen C. Propofol infusion for sedation of children. Crit Care Med 1990;18:890-2.

15 Matthews AJ. Sedation, muscle relaxation, and analgesia in PICU. Care of the Critically III 1991;8:34.

16 Rodgers EM. Diprivan intensive care sedation in children. $\mathrm{Br} f$ Anuesth 1991:67:505.

17 Kauffman RE. Fentanyl, fads, and folly: who will adopt the therapeutic orphans? f Pediatr 1991;119:588-9.

(Accepted 30 fulv 1992)

\section{ONE HUNDRED YEARS AGO}

Funeral Reform.-The Funeral Reform Association has recently held a series of meetings in London. A conference was held at the Church House under the presidency of Earl Fortescue, at which Dr. W. T. Greene read a paper on the insanitary state of St. Giles's Cemetery, Camberwell, and it was resolved to present a memorial to the Local Government Board on the subject. A drawing room meeting was held at Lady Frederick Cavendish's, and was addressed by, among others, Archdeacon Donne, Dr. Needham, Professor Flower,
Dr. Norman Kerr, and General Lowry. A tent was exhibited suitable for the protection of mourners at the grave side. The annual meeting was held at the Church House, under the presidency of the Bishop of Wakefield. Resolutions were adopted in favour of a simple earth-toearth burial with the use of antiseptics, and recommending cemetery authorities to take special precautions for the preservation of the health of mourners in inclement weather.

(BMF 1892;ii:71) 